\title{
Teens and Indoor Tanning: Time to Act on the US Food and Drug Administration's Black-Box Warning
}

\author{
Mark Gottlieb, JD ${ }^{1}$, Sophie J. Balk, $\mathrm{MD}^{2,3}$, Alan C. Geller, MPH, $\mathrm{RN}^{4}$, and Jeffrey E. Gershenwald, $\mathrm{MD}^{5,6}$ \\ ${ }^{1}$ Public Health Advocacy Institute, Northeastern University School of Law, Boston, MA; ${ }^{2}$ Children's Hospital at \\ Montefiore, Bronx, NY; ${ }^{3}$ Albert Einstein College of Medicine, Bronx, NY; ${ }^{4}$ Department of Social and Behavioral \\ Sciences, Harvard School of Public Health, Boston, MA; ${ }^{5}$ Department of Surgical Oncology, The University of Texas MD \\ Anderson Cancer Center, Houston, TX; ${ }^{6}$ Department of Cancer Biology, The University of Texas MD Anderson Cancer \\ Center, Houston, TX
}

On 27 May 2014, the US Food and Drug Administration (FDA) issued an order requiring that sunlamp products used in tanning salons carry a visible boxed warning that states: "Attention: This sunlamp product should not be used on persons under the age of 18 years". "This order, and other requirements for these products, are unprecedented, representing "an important step... to address the risk to public health from sunlamp products". ${ }^{2}$

The FDA order follows, in part, from the passage of state under-18 indoor tanning bans, which are rapidly accelerating. Following California's ban in 2011, ten other states have since passed under-18 legislation (Vermont, Nevada, Texas, Oregon, Illinois, Washington, Minnesota, Hawaii, Louisiana, Delaware).

The FDA is authorized to regulate sunlamp products as medical devices. The new order comes with the FDA's reclassification of ultraviolet (UV) sunlamp products. The reclassification from a 'low-risk' Class I device to a 'moderate-risk' Class II device requires stricter controls for design and safety. The order follows recommendations of a meeting of outside experts convened by the FDA in March 2010 and subsequent comments from the public, advocacy groups, the indoor tanning industry, and others.

FDA boxed ("black-box") warnings, familiar to prescribers of drugs, advise clinicians that "There is an

\section{(C) Society of Surgical Oncology 2014}

First Received: 7 November 2014; Published Online:17 December 2014

J. E. Gershenwald, MD

e-mail: jgershen@mdanderson.org adverse reaction so serious in proportion to the potential benefit... that it is essential that it be considered in assessing the risks and benefits of using the drug". ${ }^{3}$ The black-box warning for sunlamp products results from mounting evidence that exposure to UV radiation from tanning devices raises the risk of developing skin cancer, including melanoma, the most commonly fatal form of skin cancer.

The incidence of melanoma in the US has risen far more in young women (ages 15-39 years) than in young men over the last 30 years. Initiating indoor tanning at a young age confers significantly increased risk. ${ }^{4}$ Many authorities believe that the dramatic rise in skin cancer seen in young US women is due, at least in part, to the far higher prevalence of indoor tanning in young women compared with young men.

In a 2011 national survey of 5,600 high-school students, $13.3 \%$ reported using indoor tanning devices at least once in the past year, with $20.9 \%$ usage by girls being reported. Use increased with age, with more than one-quarter of all 17-year-old girls reporting use (Table 1). ${ }^{4}$ The notion that most teens who tan indoors do so exclusively for their high-school prom is a popular myth. Among 17-year-old non-Hispanic White girls who tan, an alarming $62 \%$ reported doing so ten or more times in $2011 .^{5}$

Several factors probably contribute to why teens tan indoors and why many do so frequently. Low-cost packages that offer multiple or unlimited visits have been reported as one reason. Teens likely fail to recognize their own increased future cancer risk posed by indoor tanning, even though melanoma is now the second most common cancer in women aged 20-29 years. ${ }^{6}$ 
TABLE 1 Indoor tanning among US high school students: National Youth Risk Behavior Survey 2011 (adapted from Guy GP Jr et al. ${ }^{4}$ )
Data are expressed as $\%(95 \% \mathrm{CI})$

CI confidence interval

\begin{tabular}{llll}
\hline Characteristic & Total & Female & Male \\
\hline $\begin{array}{l}\text { Total } \\
\text { Age, years }\end{array}$ & $13.3(11.2-15.7)$ & $20.9(17.7-24.7)$ & $6.2(4.8-7.8)$ \\
$\leq 14$ & $8.1(6.2-10.5)$ & $11.2(7.8-15.9)$ & $4.2(2.7-6.5)$ \\
15 & $8.7(7.0-10.8)$ & $12.7(10.0-16.1)$ & $5.0(3.5-6.9)$ \\
16 & $13.6(11.0-16.6)$ & $22.1(17.9-27.0)$ & $5.6(4.0-7.8)$ \\
17 & $17.3(13.9-21.2)$ & $27.9(23.0-33.5)$ & $7.2(4.9-10.4)$ \\
$\geq 18$ & $18.7(15.7-22.1)$ & $31.5(25.7-38.1)$ & $8.7(6.0-12.4)$ \\
Race/ethnicity & & & \\
Non-Hispanic White & $17.4(14.5-20.6)$ & $29.3(25.1-33.9)$ & $6.2(4.4-8.8)$ \\
Non-Hispanic Black & $3.9(2.6-5.7)$ & $3.3(2.0-5.3)$ & $4.5(2.8-7.1)$ \\
Hispanic & $7.6(6.1-9.6)$ & $9.6(7.1-12.8)$ & $5.7(4.2-7.7)$ \\
Non-Hispanic, other & $9.0(7.0-11.5)$ & $9.8(7.0-13.6)$ & $8.2(5.7-11.7)$ \\
\hline
\end{tabular}

As a result of increased skin cancer risk, the World Health Organization, American Academy of Pediatrics, American Medical Association, American Academy of Dermatology, American Cancer Society, and others including cancer centers, have recommended banning under-18 salon access. In July 2014, the US Surgeon General issued a 'Call to Action to Prevent Skin Cancer', which included, among the five goals, reducing harms from indoor tanning. ${ }^{7}$ Some nations, including France, Germany, Austria, and the UK, ban access for minors, and a population-wide ban of tanning beds takes effect throughout Australia on 1 January 2015, making it the second country, after Brazil, to completely ban their use. With high rates of tanning bed use in the US beyond the teen years, policymakers should also consider a similar ban in the US.

While it is laudable that the FDA now requires a warning label that UV tanning devices not be used by minors, it has fallen short of requiring an outright ban on access for minors. Further FDA actions may be forthcoming but it appears that, for now, it is still up to each state to enact such bans. Of all available legislative approaches, age restrictions are the most effective in preventing teens from tanning. ${ }^{8}$

Lobbying efforts by the indoor tanning industry are the most significant barrier to state indoor tanning legislation. ${ }^{9}$ Its first major trade group, the Indoor Tanning Association, settled charges brought by the US Federal Trade Commission in 2010 alleging that the industry deceptively misrepresented the risks posed by indoor tanning. ${ }^{10}$ A 2012 report by the minority staff of the House Committee on Energy and Commerce found that $80 \%$ of tanning salons told investigators that indoor tanning was beneficial to fairskinned teenage girls, while $90 \%$ of tanning salons denied that sunlamp use posed any health risks to this vulnerable group. ${ }^{11}$ In 2014, the New York State Attorney General concluded an investigation into a national tanning chain that claimed in its marketing that indoor tanning reduces heart disease, diabetes and obesity, and that sunlight prevents skin cancer and other cancers. A settlement was reached prohibiting that chain from making any health claims or targeting high-school students in its New York marketing. ${ }^{12}$

When the FDA issues a black-box warning for a prescription medication or medical device, it communicates associated potentially serious and life-threatening risks to the consumer and, significantly, to the healthcare provider. However, in this instance, the agency's warning requires action from a for-profit industry without the involvement of a conventional healthcare provider. Here, the clinician's familiar role in vetting black-box warnings (i.e. for patient safety) is assumed by an industry with a long-standing history of deceptive consumer communications. With the FDA's new order, responsibility is shifted toward the tanning bed industry, namely tanning bed operators and manufacturers.

The FDA action leaves state governments to assert their powers to regulate adherence to the FDA's black-box warning that minors should not use sunlamps. Following on the heels of the new federal warning, every state could pass legislation prohibiting tanning salons from providing indoor tanning services to persons under the age of 18 years. Early 2015 legislative hearings in many states with pending legislation will provide an initial litmus test for such actions.

Physicians, including pediatricians, dermatologists, surgical and medical oncologists, their organizations, and others who have collectively played vital roles in enacting bans in 11 states to date, must sustain their engagement. Educating policy makers about the harmful effects of artificial UV exposure for youth is essential to effective legislative campaigns, ultimately ensuring that the FDA's black-box warning is heeded. Clinicians should also continue to provide counseling to teens and their families about avoiding indoor tanning, emphasizing the meaning of 
the black-box warning. Together, state legislators and the medical/advocacy community should seize this significant opportunity to reduce the incidence of one of our nation's most preventable cancers.

ACKNOWLEDGMENT Supported in part by the generous philanthropic contributions to The University of Texas MD Anderson Moon Shots Program.

DISCLOSURE None.

\section{REFERENCES}

1. Department of Health and Human Services, Food and Drug Administration. 21 CFR Part 878. [Docket No. FDA-2013-N0461]. General and plastic surgery devices: reclassification of ultraviolet lamps for tanning, henceforth to be known as sunlamp products and ultraviolet lamps intended for use in sunlamp products. http://www.gpo.gov/fdsys/pkg/FR-2014-06-02/pdf/2014-12 546.pdf. Accessed 28 Nov 2014.

2. US Food and Drug Administration. FDA to require warnings on sunlamp products. http://www.fda.gov/NewsEvents/Newsroom/ PressAnnouncements/ucm399222.htm. Accessed 28 Nov 2014.

3. Department of Health and Human Services. Food and Drug Administration. Guidance for Industry. Warnings and precautions, contraindications and boxed warnings sections of labeling for human prescription drugs and biological products-content and format. http://www.fda.gov/downloads/Drugs/GuidanceCompliance RegulatoryInformation/Guidances/ucm075096.pdf. Accessed 28 Nov 2014.

4. Guy GP Jr, Berkowitz Z, Tai E, Holman DM, Jones SE, Richardson LC. Indoor tanning among high school students in the United States, 2009 and 2011. JAMA Dermatol. 2014; 150:501-511.
5. Guy GP, Berkowitz Z, Watson M, Holman DM, Richardson LC. Indoor tanning among young non-Hispanic white females. JAMA Intern Med. 2013;173:1920-1922.

6. Wu X, Groves FD, McLaughlin CC, Jemal A, Martin J, Chen VW. Cancer incidence patterns among adolescents and young adults in the United States. Cancer Cause Control. 2005;16(3): 309-320.

7. US Department of Health and Human Services. The Surgeon General's call to action to prevent skin cancer. Washington, DC: US Department of Health and Human Services, Office of the Surgeon General; 2014. http://www.surgeongeneral.gov/library/ calls/prevent-skin-cancer/call-to-action-prevent-skin-cancer.pdf. Accessed 24 Nov 2014.

8. Guy GP, Berkowitz A, Jones SE, Olsen EO, Miyamoto HN, Michael SL, et al. State indoor tanning laws and adolescent indoor tanning. Am J Public Health. 2014;104:e69-e74.

9. Obayan B, Geller AC, Resnick EA, Demierre MF. Enacting legislation to restrict youth access to tanning beds: a survey of advocates and sponsoring legislators. J Am Acad Derm. 2010;63: 63-70.

10. US Federal Trade Commission. Indoor Tanning Association settles FTC charges that it deceived consumers about skin cancer risks from tanning. FTC File No. 0823159. (January, 2010) Available at:http://www.ftc.gov/opa/2010/01/tanning.shtm. Accessed 11 Dec 2014.

11. US House of Representatives Committee on Energy and Commerce. New report reveals indoor tanning industry's false and misleading practices. February 1, 2012. Available at http:// democrats.energycommerce.house.gov/index.php?q=news/newreport-reveals-indoor-tanning-industry-s-false-and-misleadingpractices. Accessed 28 Nov 2014.

12. Attorney General of the State of New York Health Care Bureau. In the Matter of 750 6th Avenue Tans, LLC. Assurance No. 14039, March 24, 2014. http://www.ag.ny.gov/sites/default/files/ pdfs/bureaus/health_care/new/2014-03-24\%20Hollywood\%20Tans \%20NYC_BC.pdf. Accessed 28 Nov 2014. 